\title{
A Survey of Correlation Infertility Self-Efficacy with Behavioral Health Scales in Infertile Women
}

\author{
Mahbobeh Faramarzi' ${ }^{1}$, Hajar Pasha ${ }^{1}$, Seddigheh Esmailzadeh ${ }^{1}$, Farzan Kheirkhah ${ }^{2}$, \\ Karimollah Hajian-Tilaki ${ }^{3}$, Hajar Salmalian ${ }^{1}$ \\ ${ }^{1}$ Fatemeh Zahra Infertility and Reproductive Health Research Center, Babol University of Medical Sciences, \\ Babol, Iran \\ ${ }^{2}$ Department of Psychiatry, Faculty of Medicine, Babol University of Medical Sciences, Babol, Iran \\ ${ }^{3}$ Department of Social Medicine and Health, Faculty of Medicine, Babol University of Medical Sciences, Babol, \\ Iran \\ Email: Mahbob330@yahoo.com, ${ }^{*}$ pashahajar@yahoo.com, salmalian2005@yahoo.com
}

Received 25 February 2014; revised 29 March 2014; accepted 7 April 2014

Copyright (C) 2014 by authors and Scientific Research Publishing Inc.

This work is licensed under the Creative Commons Attribution International License (CC BY). http://creativecommons.org/licenses/by/4.0/

(c) (i) Open Access

\section{Abstract}

Background: Infertility is a unique medical challenge that can have health behavioral consequence on infertile women including lack of self-esteem, depression, anxiety, fertility problem in infertile couples. The aim of this study was to evaluate correlation between self-efficacy and health behaviors scales in infertile women. Methods: A cross sectional study was conducted on 89 infertile women with mild to moderate depression (Beck scores 10 - 47) who were recruited from Fatemeh Zahra Infertility and Reproductive Health Research Center. All participants completed Self-efficacy Inventory (ISE) and other health behavioral scales (e.g., the Beck Depression Inventory (BDI), Cattle Anxiety Scale (CAS), Fertility Problem Infertility (FPI), and GHQ). Pearson correlation coefficient and Spearman rho correlation coefficient were used to analyze the data. Variables were included in the study if they had a p-value of $<0.05$. Statistical analysis was performed SPSS 17 . Results: The most of participants had totally high confident $53.9 \%, 41.6 \%$ moderately confident, and $4.5 \%$ low confident. Mean ISE score $( \pm S D)$ for the overall infertile women was in the moderate range $(6.18 \pm 1.39)$. The lowest mean score in subscales of self-efficacy that infertile women reported was item "Accept that my best efforts may not change my/our infertility" (4.90 \pm 3.41$)$. There was the significant relationship between ISE with job $(p=0.016)$ and residency $(p=0.016)$ of infertile women. The employed infertile women have twice higher self-efficacy than unemployed women $(62.7 \%$ vs $37.9 \%)$ and those who lived in the city had a higher level of confidence $(75 \%$ vs. $53 \%)$. The infertile women with older age, higher education, and the more duration of

"Corresponding author. 
infertility have the lower self-efficacy. There is the significantly negative correlation between the mean of ISE score with BDI $(p=0.018)$, overt anxiety $(p=0.11)$, CAI $(p=0.018)$, social concern of FPI $(p=0.003)$, and marital concern of FPI $(0.025)$. Also a significant tendency was found between ISE and occult anxiety among infertile groups $(p=0.1)$. There is the significantly positive correlation between the mean of ISE score with GHQ $(p=0.004)$. Conclusions: Self-efficacy related to health behaviors scales, suggesting that having a psychological intervention can also facilitate the process of promoting self-efficacy.

\section{Keywords}

Infertility, Self-Efficacy, Depression, Stress, Anxiety, Health Behaviors, Fertility Problem

\section{Introduction}

Infertility is a health problem [1]. The infertile women have problems in coping with emotional liability during diagnosis and treatment and a sense of fear and failure [2]. There is a negative psychological consequence such as depression, anxiety, sense of loss, feeling of isolation and lowered self-esteem in women that experienced infertility treatment [3]. Self-efficacy based on Bandura's self-efficacy theory, is defined as confidence and selfesteem in a socially acceptable behavior [4]. Self-efficacy is a person's belief in his or her capacity to succeed in a particular situation. Bandura reported that these beliefs can affect on how person think, act, and feel [5]. The several studies showed that self-efficacy has the important role in health promotion and outcome [5] [6].

The researchers showed that infertility self-efficacy had relationship with health behavioral scales. Infertile women with higher levels of infertility self-efficacy reported fewer depressive symptoms, anxiety, and higher general health from infertility experience [7]-[9]. As, few studies have examined on the correlation self-efficacy with other health behavioral scales and there are no published data about this subject in Iranian infertile women set, therefore this study conducted to evaluate the correlation infertility self-efficacy with health behaviors scales in a sample of Iranian infertile women.

\section{Methodology}

A cross sectional study was conducted in Fatemeh Zahra Infertility and Reproductive Health Research Center of the Babol University of Medical Sciences (2007) for nine months. The project was conducted according to Iranian Research Clinical Trial and was approved by Ethical committee of Babol University of medical science. After coordination and receiving justification from Infertility Council, infertile women who had dossier there, were recruited for this study.

\subsection{Data Collection}

Five midwives of the center conducted structured telephone invitations with potential participants. Of 350 invitations, 200 patients accepted to enter the study and were referred to the center. Subsequent to completing the demographic questionnaire and the Beck Depression Inventory (BDI), a psychologist conducted a face-to-face interview. Finally, 89 participants remained until the end of the study. All participants completed the Self-Efficacy Inventory (SEI) and other health behavioral scales including: Beck Depression Inventory (BDI), Cattle Anxiety Scale (CAS), Fertility Problem Infertility (FPI), and General Health Questionnaire (GHQ) at the beginning of the study. Used Scales were reliable instruments to assess behavioral health status.

\subsection{Inclusion and Exclusion Criteria}

Women with these characteristics were invited to this study: age of less than 45, more than five years education, more than two years of infertility, having at least one IVF. Women who met one of the following conditions were excluded from the study: a score $\leq 9$ or $>47$ on the BDI, or meeting the criteria for clinical severe depression on the clinical interview. Thus, only women with minimal, mild, and moderate depression (Beck score 10 47) were included the study. 


\subsection{Analysis}

All statistical analyzes were performed using SPSS software (version 17.0). Descriptive statistics were used to describe the mean scores $( \pm \mathrm{SD})$ and proportion. Pearson correlation coefficient and Spearman rho correlation coefficient were used to evaluate the relationship of ISE and other behavioral health Scale in infertile women. The p-value of $<0.05$ was considered as significant level. It should be noted that results of this articles is a part of extend project that implemented in Fatemeh Zahra Infertility and Reproductive Health Research Center of the Babol University of Medical Sciences. Comparison pharmacotherapy and psychotherapy in improvement depression, anxiety, and general health reported in previous publications [10] [11]. This article focuses on correlation between infertility self-efficacy with other health behavior scales.

\section{Results}

The mean age $( \pm \mathrm{SD})$ of infertile women and their husbands were $28.87 \pm 4.89$ and $33.16 \pm 5.06$ respectively. The majority of infertile women were housewives (95.4\%) and living urban area (67\%). The average duration of infertility was $5.81 \pm 3.95$ years. The most common cause of infertility was related to female factors (37.2\%). The mean of ISE Score was $6.181 \pm 1.39$. The most of participants did have totally high confident (53.9\%), $41.6 \%$ had moderately confident and only $4.5 \%$ had low confident (Figure 1).

The Characteristics of the 16 items in ISE scale are summarized in Table 1. One of the lowest mean score in self-efficacy that infertile women reported was item "Accept that my best efforts may not change my/our infertility" $(4.90 \pm 3.41)$.

The results of Nonparametric correlations showed that ISE Score had the significant relationship with residency $(p=0.003)$, and women job $(p=0.016)$. The infertile women who were employed and residency of theirs were in city have the higher self-efficacy score. The employed infertile women had twice higher self-efficacy than unemployed women (62.7\% vs $37.9 \%$ ) and those who lived in the city had a higher level of confidence (75\% vs. 53\%). The infertile women with older age, higher education, and the more duration of infertility had the lower self-efficacy.

In this study, significant correlations were exhibited for ISE with other behavioral health scales. There were the significantly negative correlation between the mean of ISE score with BDI $(\mathrm{p}=0.018)$, overt anxiety $(\mathrm{p}=$ $0.11)$, CAI ( $p=0.018)$, social concern of FPI $(p=0.003)$, and marital concern of FPI $(0.025)$. Also a significant tendency was found between ISE and occult anxiety among infertile groups $(\mathrm{p}=0.1)$ (Table 2$)$.

\section{Discussion and Conclusions}

Our findings showed that almost half of the infertile women were with low and moderate self-efficacy (46.1\%). Principally, experience of infertility had highly stressful for infertile women [12] and it decreased self-confidence [13] [14]. Studies showed that there was sense of loss, feeling of isolation and lowered self-esteem in women that experienced infertility treatment [3] and infertility can be associated with psychological consequences such as decreased self-efficacy [15].

The results approved that item "Accept that my best efforts may not change my/our infertility" was one of the lowest mean score in subscales of self-efficacy inventory. A similar findings has been reported in others studies. Benyamin et al. reported that not being able to solve the problem myself was one of the most significant

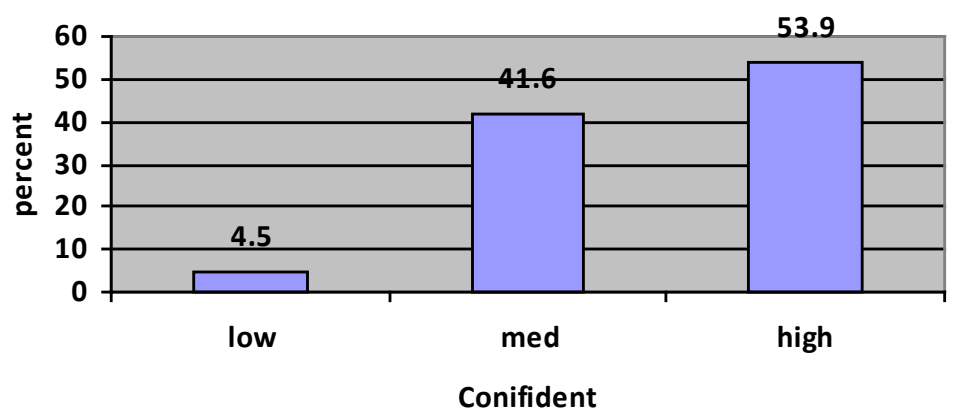

Figure 1. Frequency of level self-efficacy in infertile women. 
Table 1. Characteristics of the 16 ISE items.

\begin{tabular}{cc}
\hline ISE item & Mean score (range 1 - 9) (before) \\
\hline Ignore or push away unpleasant thoughts that can upset me during medical procedures & $\mathbf{6 . 3 4 ( 2 . 6 0 )}$ \\
Keep a sense of humor & $\mathbf{6 . 4 3 ( 2 . 5 6 )}$ \\
Make meaning out of my infertility experience & $\mathbf{7 . 2 2 ( 2 . 5 8 )}$ \\
Handle mood swings caused by hormonal treatments & $\mathbf{5 . 8 8 ( 2 . 5 2 )}$ \\
Keep from getting discouraged when nothing I do seems to make a difference & $\mathbf{5 . 0 0 ( 3 . 0 8 )}$ \\
Accept that my best efforts may not change my/our infertility & $\mathbf{4 . 9 0 ( 3 . 4 1 )}$ \\
Control negative feelings about infertility & $\mathbf{6 . 6 9 ( 2 . 5 4 )}$ \\
Cope with pregnant friends and family members & $\mathbf{7 . 3 2 ( 2 . 3 5 )}$ \\
Handle personal feelings of anger or hostility & $\mathbf{7 . 1 8 ( 2 . 0 3 )}$ \\
Keep a positive attitude & $\mathbf{7 . 3 4 ( 2 . 0 7 )}$ \\
Lessen feelings of self-blame, shame, or defectiveness & $\mathbf{6 . 7 6 ( 2 . 3 6 )}$ \\
Stay relaxed while waiting for appointments or test results & $\mathbf{5 / 0 0 ( 3 . 1 0 )}$ \\
Do something to make myself feel better if I am sad or discouraged & $\mathbf{6 . 8 5 ( 2 . 4 4 )}$ \\
Feel good about my body and myself & $\mathbf{6 . 2 6 ( 2 . 6 6 )}$ \\
Keep active with my usual life routine & $\mathbf{6 . 8 2 ( 2 . 4 1 )}$ \\
Feel like a sexual individual & $\mathbf{6 . 1 5 ( 2 . 7 2 )}$ \\
Total ISE & $\mathbf{6 . 1 8 ( 1 . 3 9 )}$
\end{tabular}

Table 2. Correlations of ISE to other behavioral health measures and related variables.

\begin{tabular}{|c|c|c|}
\hline Variable & Correlations with ISE & Interpretation \\
\hline $\mathrm{BDI}^{*}$ & -0.251 & Moderate significant negative association $(p=0.018)$ \\
\hline $\mathrm{CAI}^{*}$ & -0.251 & Moderate significant negative association $(p=0.018)$ \\
\hline Overt anxiety & -0.266 & Moderate significant negative association $(p=0.011)$ \\
\hline Occult anxiety & -0.141 & A significant negative tendency association $(p=0.1)$ \\
\hline $\mathrm{GHQ}^{*}$ & 0.311 & High significant positive e association $(\mathrm{p}=0.004)$ \\
\hline FPI $^{*}$ & 0.072 & No association \\
\hline Social concern of FPI & -0.312 & High significant negative association $(p=0.003)$ \\
\hline Marital concern of FPI & -0.237 & Moderate significant negative association $(p=0.025)$ \\
\hline Rejection of childfree lifestyle of FPI & -0.125 & No association \\
\hline Sexual concern & -0.125 & No association \\
\hline Age & -0.033 & No association \\
\hline Husband age & -0.032 & No association \\
\hline Education & -0.058 & No association \\
\hline Husband education & -0.022 & No association \\
\hline Job & 0.258 & Moderate significant positive association $(\mathrm{p}=0.016)$ \\
\hline Economic status & -0.135 & No association \\
\hline Residency & -0.318 & High significant negative association $(p=0.003)$ \\
\hline Duration infertility & -0.041 & No association \\
\hline Kind of infertility & 0.074 & No association \\
\hline Cause of infertility & 0.082 & No association \\
\hline IUI & -0.052 & No association \\
\hline Outcome of IUI & -0.058 & No association \\
\hline
\end{tabular}

*BDI: Beck Depression Inventory; CAI: Cattle Anxiety Inventory; GHQ: General Health Questionnaire; FPI: Fertility Problem Inventory. 
difficulties in infertile women [16], and the women infertile are confronted with sensations of insecurity, and hopeless [17]. In relation ISE score with demographic characteristics, our results showed that there were the negative correlation between the ISE score and age, education, and duration of infertility that of course wasn't significant difference. The infertile women with older age, higher education, and the more duration of infertility had the lower self-efficacy. In contrast, a similar study reported that there isn't significant association between ISE and relevant variables such as age, income, cause of infertility [18]. While many studies showed that infertile women inclined to be confident about their ability to become pregnant at the onset of infertility treatment, but after lasting a long period of time treatment they experience distress and hopeless [19]. Also, failure in treatment programs can be effective in reducing self-esteem and self-efficacy of infertile women [20]. In addition Najmi et al. reported that infertility causes feelings of worthlessness and incompetence, particularly with prolonged therapy [21].

This project showed that infertile Women's ISE scores correlated significantly with job and residency. Employed women's and who residency of theirs was in city tended to have significantly higher self-efficacy scores on the ISE. The employed infertile women have twice higher self-efficacy than unemployed women and those who lived in the city had a higher level of confidence than living in rural. It seems that if one has the financial resources to pay the cost of infertility treatment, self-efficacy may be increased. Since, employed infertile women have financial independence, therefore are less affected by stress caused poverty and they with more confidence to continue the infertility treatment process.

Our results showed that infertility self-efficacy has significantly correlation with other behavioral health. There was the significantly negative correlation between ISE with BDI, CAI, GHQ, Overt anxiety. Infertile women with higher levels of infertility self-efficacy as measured by the ISE scale also report fewer depressive symptoms, anxiety, and higher general health from infertility experience. These results are largely consistent with previous assessments of infertility self-efficacy [7] [8] [22]. Self-efficacy is the belief of person about the skill and ability to control one's behavior to achieve a specific goal [23]. Perceived self-efficacy in one's ability to control events that affect their lives [8], Bandura believes that perceived self-efficacy is considered an important component in individual performance and also it is as a predictor factor in accepting patterns of health and sexual behavioral [22]. The studies showed that infertility stressful situation can influence on personal control [7]. A person with high self-efficacy can try the more in the new behavior health [24]. Strong sense of self-efficacy can increase individual welfare and performance in different ways such as ability to cope with obstacles. On the other hand, viewpoints of people with low self-efficacy it harder than something that really exists [9]. In the same study reported that negative image of themselves and their bodies could be associated with anxiety and depression [25]. The infertile women have lower self-efficacy, lower life satisfaction, more depression, and feeling more guilt [26].

Present study showed the negative correlation between ISE and some of dimensions of problem fertility inventory (FPI) such as social, marital, and sexual concerns. The infertile women with higher ISE score had the less social and marital concerns. It is interesting that correlation reported in the current research had parallels to those observed in a recent study on "Development and validation of the infertility self-efficacy scale [18]. Najmi et al. reported that infertility causes negative beliefs about themselves, concerns about sexual attractiveness, feeling ugly and disability, sexual disorder, physical complaints, and also the problem in marital relationship and sexuality [21]. Alizadeh et al. showed that between self-esteem and all components of stress infertility (sex, marital, social, lifestyle without the child, and need for parent) there was a significant inverse relationship, and sexual issues had the highest correlation coefficient with self-esteem [20]. Tare et al. approved that there is strongly significant negative association between ISE with perceived stress scale and fertility problem inventory [18]. A similar study suggested that infertility causes concerns about sexual attractiveness, sexual disorder, negative beliefs about their themselves, and also the problem in marital relationship and sexuality [21]. Lack of sexual self-esteem, no pleasure of sexual relationships (marital), feel pressure to plan for sexual intercourse have the most effect on self-esteem of infertile women [20]. The women infertile due to a failure to achieve desired objectives lose confidence and they are faced with lack of communication with others, sensations of insecurity, and hopeless [17]. Self-efficacy related to health behaviors scales, suggesting that having a psychological intervention can also facilitate the process of promoting self-efficacy.

\section{Summary}

In summary, this study suggests that a high self-efficacy can have the more beneficial effects in increased men- 
tal health and may be a cost effective resource for decreasing depression, anxiety, fertility problem in infertile women. Also, in surveillance program for the infertile women, it is necessary to detect and to modify the factors that lead to low self-efficacy.

\section{Acknowledgements}

We are grateful to the Vice-Chancellery and the Research and Technology Committee of Babol University of Medical Sciences for financial support of the project. Also, the authors thank all the participants who attended this study and the midwives of Fatemeh Alzahra hospital who invited and encouraged women for attending in this study

\section{Disclosures}

The authors declare that there is no conflicting interest.

\section{Financial Disclosure}

Fatemeh Zahra Infertility and Reproductive Health Research Center, Babol University of Medical Sciences, Babol, IRAN.

\section{References}

[1] Donkor, E.S. and Sandall, J. (2009) Coping Strategies of Women Seeking Infertility Treatment in Southern Ghana. African Journal of Reproductive Health, 13, 81-93.

[2] Podolska, M.Z. and Bidzan, M. (2011) Infertility as a Psychological Problem. Ginekologia Polska, 82, 44-49.

[3] Gibson, F.L., Ungerer, J.A., Tennant, C.C., Saunders, D.M. and McMahon, C. (2000) Parental Adjustment and Attitudes to Parenting after in Vitro Fertilization. Fertility and Sterility, 73, 565-574. http://dx.doi.org/10.1016/S0015-0282(99)00583-X

[4] Folkman, S. and Chesney, M. (1992) Stress and Coping and High Risk Sexual Behavior. Health Psychology, 11, 218222. http://dx.doi.org/10.1037/0278-6133.11.4.218

[5] Bandura, A. and Adams, N.E. (1994) Analysis of Self-Efficacy Theory in Behavior Change. Cognitive Therapy and Research, 1, 287-310. http://dx.doi.org/10.1007/BF01663995

[6] Mahoney, C.A., Thombs, D.L. and Ford, O.J. (1995) Health Belief and Self Efficacy Models Their Utility in Explaining College Student Condom Use. AIDS Education and Prevention, 7, 32-49.

[7] Bandura, A. (1986) Social Foundations of Thought and Action: A Social Cognitive Theory. Prentice-Hall, Englewood Cliffs.

[8] Kazdin, A.E. (2000) Encyclopaedia of Psychology. Vol. 17. Oxford University Press, 212-213.

[9] Peyman, N., Hidarnia, A., Ghofranipour, F., Kazemnejad, A., Khodaee, Gh. and Amin Shokravi, F. (2007) The Relationship between Perceived Self-Efficacy and Contraceptive Behaviors among Iranian Women Referring to Health Centers in Mashad in Order to Decrease Unwanted Pregnancies. Medical Journal of Reproduction \& Infertility, 8, 7890.

[10] Faramarzi, M., Alipor, A., Esmaelzadeh, S., Kheirkhah, F., Poladi, K. and Pasha, H. (2008) Treatment of Depression and Anxiety in Infertile Women: Cognitive Behavioral Therapy versus Fluoxetine. Journal of Affective Disorders, 10, 159-164. http://dx.doi.org/10.1016/j.jad.2007.09.002

[11] Faramarzi, M., Kheirkhah, F., Esmaelzadeh, S., Alipor, A., Hajahmadi, M. and Rahnama, J. (2008) Is Psychotherapy a Reliable Alternative to Pharmacotherapy to Promote the Mental Health of Infertile Women? A Randomized Clinical Trial. European Journal of Obstetrics, Gynecology, and Reproductive Biology, 141, 49-53. http://dx.doi.org/10.1016/j.ejogrb.2008.07.012

[12] Martins, M.V., Peterson, B.D., Almeida, V.M. and Costa, M.E. (2011) Direct and Indirect Effects of Perceived Social Support on Women's Infertility-Related Stress. Human Reproduction, 26, 2113-2121. http://dx.doi.org/10.1093/humrep/der157

[13] Pasch, L.A., Dunkel-Schetter, C. and Christensen, A. (2002) Differences between Husbands' and Wives’ Approach to Infertility Affect Marital Communication and Adjustment. Fertility and Sterility, 29, 13-26.

[14] Shabazi, L. and Salimi, T. (1999) Prevalence Depression of Infertile Couple Referred to Research Center of Infertility Yazd. The Journal of Shahid Sadoughi University of Medical Sciences, Yazd, Iran, 8, 98.

[15] Pahlavani, H., Malakouti, K. and Shahrokh Tehrani Nejad, E. (2002) Stressors, Their Coping Strategies and Relation to 
Mental Health in Infertile Individuals. Iranian Journal of Psychiatry and Clinical Psychology, 7, 87-79.

[16] Benyamini, Y., Gozlan, M. and Kokia, E. (2005) Variability in the Difficulties Experienced by Women Undergoing Infertility Treatments. Fertility and Sterility, 83, 275-283. http://dx.doi.org/10.1016/j.fertnstert.2004.10.014

[17] Seible, M.M. and Taymor, M.L. (1982) Emontional Aspects of Infertility. Fertility and Sterility, 37, 137-145.

[18] Cousineau, T.M., Green, T.C., Corsini, E.A., Barnard, T., Seibring, A.R. and Domar, A.D. (2006) Development and Validation of the Infertility Self-Efficacy Scale. Fertility and Sterility, 85, 1684-1696. http://dx.doi.org/10.1016/j.fertnstert.2005.10.077

[19] Domar, A., Clapp, D., Slawsby, E., et al. (2000) Impact of Group Psychological Interventions on Pregnancy Rates in Infertile Women. Fertility and Sterility, 73, 805-841. http://dx.doi.org/10.1016/S0015-0282(99)00493-8

[20] Alizadeh, T., Farahani, M.N., Shahraray, M. and Alizadegan, Sh. (2005) The Relationship between Self-Esteem and Locus of Control with Infertility Related Stress of No Related Infertile Men and Women. Medical Journal of Reproduction \& Infertility, 6, 204.

[21] Najmi, B., Ahmadi, S. and Ghasemi, G. (2002) Psychological Characteristics of Infertile Couples Referred to Infertility Center of Isfahan City. Medical Journal of Reproduction \& Infertility, 2, 40-45.

[22] Bandura, A. (1997) Self-Efficacy: Toward a Unifying Theory of Behavioral Change. Psychological Review, 84, 191215. http://dx.doi.org/10.1037/0033-295X.84.2.191

[23] Maibach, E., Schlenger, W., Stein, J.A. and Murphy, D.A. (2001) Conceptualizing the Multidimensional Nature of Self-Efficacy: Assessment of Situational Context and Level of Behavioral Challenge to Maintain Safer Sex. Health Psychology, 20, 281-290. http://dx.doi.org/10.1037/0278-6133.20.4.281

[24] Doak, C.C., Doak, L.G. and Root Jane, H. (1996) Teaching Patients with Low Literacy Skills. 2nd Edition, Lippincott Co, Philadelphia, 57-68.

[25] Beck, A.T. (1973) The Diagnosis and Management of Depression. University of Pennsylvania Press, Philadelphia.

[26] Berg, B.J., Wilson, J.F. and Weingartner, P.J. (1991) Psychological Sequel of Infertility Treatment. The Role of Gender and Sex-Role Identification. Social Science \& Medicine, 33, 1071-1080. http://dx.doi.org/10.1016/0277-9536(91)90012-2 